\title{
UTILIZATION OF BLENDED LEARNING TO TEACH PRECLINICAL ENDODONTICS
}

\author{
Cristina Maresca, DDS, MS
}

A thesis submitted to the faculty of the University of North Carolina at Chapel Hill in partial fulfillment of the requirements for the degree of Master of Science in the Department of Endodontics, School of Dentistry

\section{Chapel Hill}

2013

Approved by

Eric Rivera DDS, MS

Wallace Hannum, PhD

Sompop Bencharit, DDS, PhD

Carlos Barrero, BDS, MS 
(C) 2013

Cristina Maresca DDS, MS

ALL RIGHTS RESERVED 


\begin{abstract}
CRISTINA MARESCA: Utilization of Blended Learning to Teach Preclinical Endodontics (Under the direction of Dr. Eric Rivera)
\end{abstract}

Blended Learning (BL) is the integration of classroom learning with an online environment. The purpose of this study was to determine whether dental students who experience BL in a preclinical Endodontic course could demonstrate better manual skills, conceptual knowledge, and learning experience compared to those utilizing traditional learning. Students $(n=81)$ were assigned to either traditional or BL groups. A root canal procedure was used to determine the level of manual skills gained by each group. Pre and post-assessment quizzes were given to all students to evaluate conceptual knowledge gain. The student perspectives were evaluated using a Qualtrics survey. The BL group scored better than the traditional group on the manual skills exercise at a statistically significant level. There were no differences in the post-quiz scores between the two groups. Students' opinions were positive regarding BL. With BL, students were able to learn and demonstrate dental skills at a high level. 
To my husband Mark, thank you for your support, love and bringing so much happiness into my life. And my mother, for her continued support and help with my angels: Sofia and Gabriella.

I would not have accomplished this without you

Love you. 


\section{ACKNOWLEDGMENTS}

Dr. Carlos Barrero, for your support and guidance during the process of my thesis work, and for sharing my passion for teaching.

Dr. Eric Rivera, for your unwavering support, understanding and guidance, and for giving the opportunity to be an Endodontist and make my dream come true.

Dr. Derek Duggan, for your enthusiasm and trust during the course of the whole project.

Dr. Enrique Platin, for your help, advice, and good discussions.

Dr. Wallace Hannum, for your help and contribution to this project.

Dr. Ceib Phillips, for your invaluable assistance with the statistical analysis.

Center for Educational Development \& Informatics: Mrs. Ramona Hutton-Howe, for all your help with the video production and editing, Mr. Tarrl Morley for your help and advice recording the lectures and Mr. David Arnold, for all your help and patience with the SAKAI platform.

Ivan Saldarriaga: for all your help with editing and proofreading.

My Co-residents, for your friendship and help with the project and making the residency program fun.

The UNC Endodontic Department, for guidance and support and enthusiasm with the project. I hope you use the material for many years to come. 


\section{TABLE OF CONTENTS}

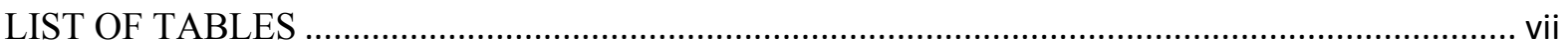

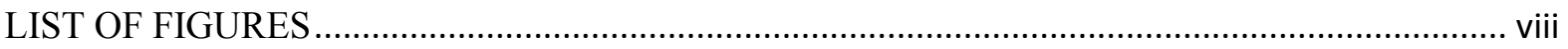

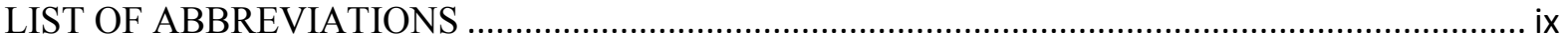

INTRODUCTION

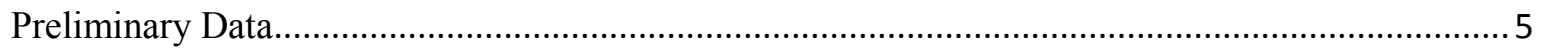

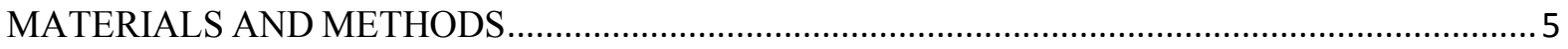

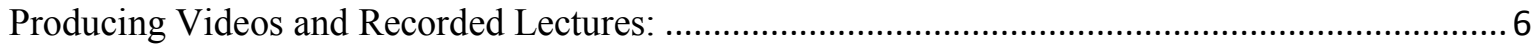

Creating and Launching SAKAI Platforms:................................................................................. 7

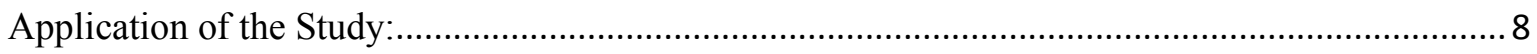

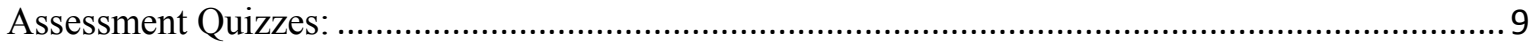

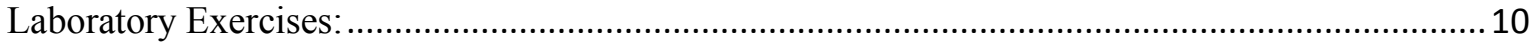

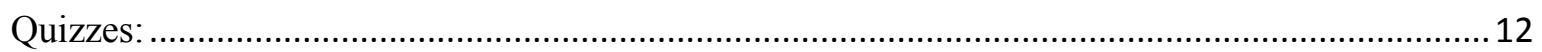

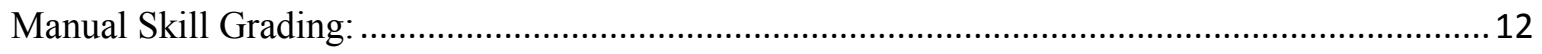

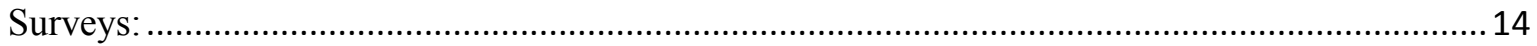

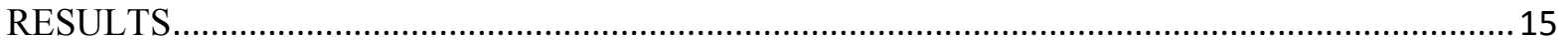

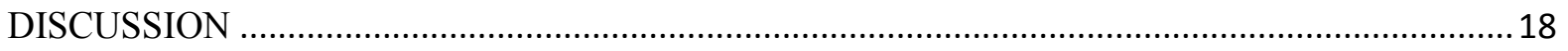

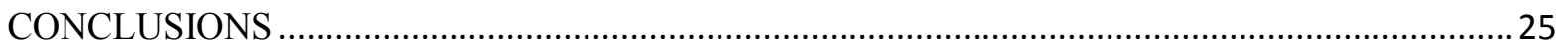

Suggestions for Implementation of Blended Learning in Dental Schools: ................................... 25

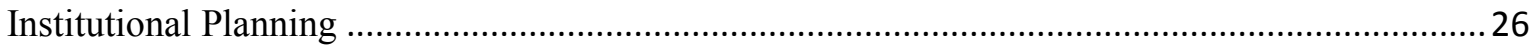

Blended Learning Faculty Development Implementation........................................................ 27

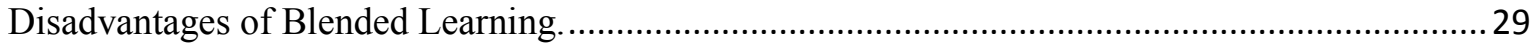

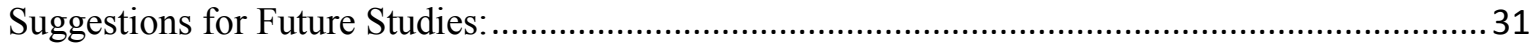

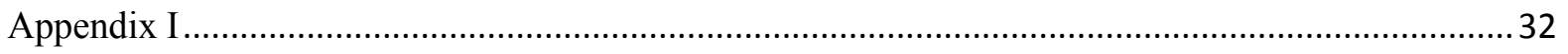

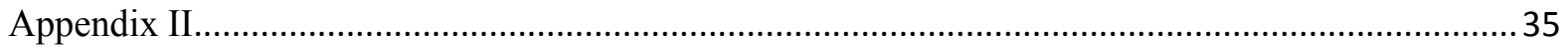

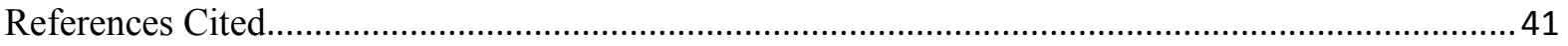




\section{LIST OF TABLES}

Page

Table \#1: Criteria were used to evaluate the endodontic treatment on the maxillary tooth ... 32

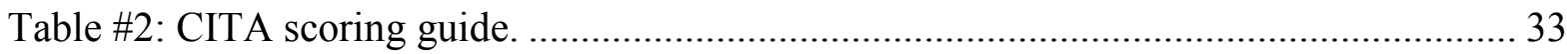

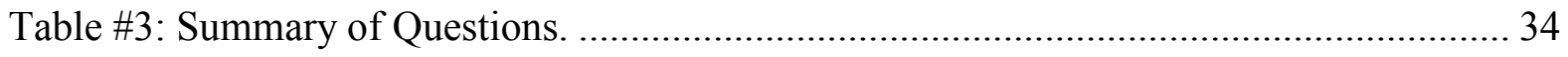




\section{LIST OF FIGURES}

Page

Figure \#1: Mean and Box Plot of grades for the knowledge pre-quiz and post-quiz scores .. 35

Figure \#2: Manual Skills RCT Competency Results: Averages and Standard Error ............ 36

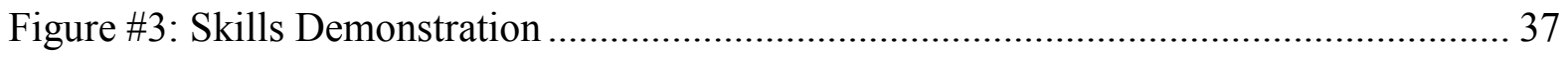

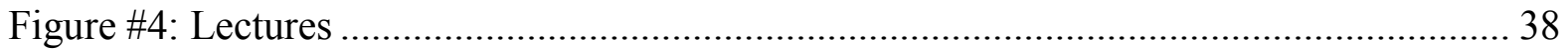

Figure \#5: Confidence in Performing RCT .................................................................... 39

Figure \#6: Satisfaction of the BL Group....................................................................... 40 


\section{LIST OF ABBREVIATIONS}

AGF

ANCOVA

BL

CBLIOM

CEDI

CITA

CMS

IOB

IOM

IRBPHS

LSM

MAF

OCIS

OLM

RCT

UNC

VLE
Apical Gauge File

Analysis of Covariance

Blended Learning

Computer Based Learning Institute of Medicine's

Center for Educational Development and Informatics

Council of Interstate Testing Agencies, Inc.

Course Management Systems

Intra Orifice Barrier

United States Institute of Medicine's

Institutional Review Board for the Protection of Human Subjects

Learning Management Systems

Master Apical File

Office of computer and Information systems

Online Learning Module

Root Canal Treatment

University of North Carolina

Virtual Learning Environments 


\section{INTRODUCTION}

Traditionally, the undergraduate preclinical Endodontics course is taught using a face-to-face (synchronous) learning approach. In this method, the faculty demonstrates a clinical technique using, commonly, a PowerPoint presentation in a lecture hall; students then perform the same technique in a simulated clinic environment. Face-to-face (synchronous) learning can be problematic because information is delivered at one time without any interactivity or opportunity to repeat all or even any of the segments of the lecture. Face-to-face learning is believed to be a passive learning approach. It is expected that all the students will process the presented information in the same way, not allowing students to review important concepts of the presentation. Therefore, some students excel, most students eventually complete the task, and a few struggle. A possible solution to address these issues is to teach the undergraduate preclinical Endodontics course using a blended learning (BL) approach, which is a combination of synchronous (face-to-face) and asynchronous (online technology-mediated learning modules) approaches. ${ }^{1}$ Creating a multimedia learning module that presents the knowledge and demonstrates the skills will allow students to absorb course instructions not only when instructional material is presented for first time but also permits students to access and review the material at a later opportunity when it is most convenient for them to concentrate. The BL approach even allows the students to review the material multiple times if they require. Frequently, students need to have access to demonstration techniques even when they are 
practicing the same techniques during their laboratory session. Therefore, BL can provide a more effective teaching strategy for students' acquisition of the knowledge and skills. It has been reported that this technology can also help dental educators overcome challenges such us faculty shortages, limited funds, demands, and even meet expectations of reducing lecture time in an already saturated curriculum. ${ }^{2,3}$

Computers in dentistry have been used as a learning tool for many years, ${ }^{4}$ and the first computer based learning (CBL) tool was developed at the University of Kentucky. ${ }^{5}$ However, the real development did not begin until the early 1990s when several precursory CBL packages were developed. ${ }^{6,7,8}$ These were mainly distributed through floppy disks and CD-ROMs, as the Internet was not as widely utilized or as easily accessible as it is today. These CD's were mainly available to distribute as lecture material. It was not until the mid-1990s that some interactive CBL packages were available..$^{9,10,11}$

During the last decade, internet accessibility and connectivity have vastly improved, taking electronic education (e-education) from $\mathrm{CD}-\mathrm{ROMs}$ to online environments. E-education programs offer many advantages for the learner and instructor, such as increasing the student's independence by giving them "anytime, anywhere" access to educational opportunities, and allowing teachers to easily update educational materials.

E-education has progressed in recent years into the method referred to as blended learning (BL). Blended learning is the thoughtful and methodical integration of the traditional face-toface classroom learning experiences combined with online learning experiences. The main advantage of BL is that it combines the strengths of synchronous (face-to-face) and asynchronous (online modules) learning activities. ${ }^{12}$ 
Virtually all universities and dental school administrators agree that E-learning plays an important role in the future of education. ${ }^{13}$ Evidence from previous studies indicate that distance education is at least as effective, and perhaps more effective in some circumstances, than traditional classroom instruction..$^{14,15,16}$ E-learners often demonstrate increased content retention that results in improved knowledge, skills, and attitudes because students have control over the content. Advancements in E-learning are creating the groundwork for a revolution in graduate medical education by individualizing learning, enhancing learners' interactions with each other, and transforming the role of teachers from disseminators of information to facilitators of selfmotivated learning. ${ }^{17}$

In post-doctoral residency programs, interactive small group discussions are accepted as the gold standard for teaching because they challenge residents to think critically about concepts presented in assigned readings. ${ }^{14,18}$ In distance education, it is important not to sacrifice a course's key interactive components for the convenience of access and repeatability. ${ }^{19}{ }^{20}$ Based on the results of previous evaluations of interactive, distance education seminars with orthodontic residents, Miller et al. evaluated a BL approach that combined observation of recorded seminars followed by live follow-up discussion. ${ }^{21}$ Using this method with residents at eight other schools, Miller showed that distant residents learned at least as much as those physically present for the seminar, and that the distant faculty and residents found the learning experience quite acceptable, although they preferred live interaction.

Modernizing the dental curriculum with the goal of consolidating concepts and encouraging critical thinking was one of the goals of the 1995 United States Institute of Medicine's (IOM) landmark report from the Committee on the Future of Dental Education. Recommendation no. 16 advocated the implementation of a mix of actions to reduce costs and increase revenue. ${ }^{22}$ One 
potential strategy involved rethinking the basic models of dental education and experimenting with less costly alternatives. ${ }^{23}$ In recent years, more schools have moved from a traditional faceto-face interaction to an online environment. A variation of online teaching is the BL which may create the perfect teaching strategy for dental students learning preclinical Endodontics. In order to keep distance education for DDS students as cost-effective as possible while retaining interaction, a BL approach needs to be developed. Blended distance learning is an acceptable method of instruction that allows students to access various experts, supplement traditional instructor led training, and ease the strain of current faculty shortages. BL has been proposed as an alternative method for graduate orthodontic education, ${ }^{24,25}$ but has never been proposed in the area of Endodontics or in preclinical laboratory formats. As with other instruction, interaction is a key component in distance education. Researchers and practitioners agree that interaction increases learning satisfaction in distance education courses. ${ }^{17,26,27}$

BL can also help facilitate the distribution of faculty resources in highly specialized areas, resulting in greater cost effectiveness by lowering the teaching load of experience and specialized faculty and making educational resources widely available to students. In addition to these mentioned advantages, the teaching modules employed in this study allow the students to review Endodontic concepts and develop dental skills at their own pace without face-to-face interaction, enhancing teaching strategies that help maximize the student learning experience. Knowledge gained from this study might also help shape future guidelines in the development of preclinical courses in our dental school.

The general objective of this project was to determine if there are differences in acquiring manual skills and conceptual knowledge of a particular skill, such as a the completion of a maxillary endodontic root canal therapy, by second year dental students after the use of BL in a 
preclinical Endodontics course as compared to those who did not use the BL approach. This study also tested the hypothesis that a blended learning curriculum can develop competency in both pre-clinical laboratory and didactic learning with less direct supervision than with our past, traditional curriculum.

\section{Preliminary Data}

This research project was initiated during the summer semester of 2011, when a pilot study was developed to assess the effectiveness of BL in a preclinical Endodontic course for the acquisition of manual skill and conceptual knowledge placing an Intra Orifice Barrier (IOB). An additional goal of the pilot study was to gather feedback from the students who used the BL approach with respect to ease of use and helpfulness. Ten second-year dental students consented

and were randomly assigned to two groups: Students who did not use the BL approach, and students who did. Two endodontic faculty members who were masked as to each student's test group determined the total number of error points based on performance criteria. After placing the IOB, students in both groups completed a questionnaire to assess their preference for using the BL approach versus traditional lecture. The BL approach was received well by the dental students with no problems or issues. The performance of the two groups was similar.

\section{MATERIALS AND METHODS}

This study was approved by the Institutional Review Board of the University Of North Carolina School Of Dentistry at Chapel Hill. Permission was granted to test a blended learning module as a method of teaching preclinical Endodontics. A series of four lectures and six videos that were part of the preclinical Endodontics curriculum course for sophomore students were redesigned, updated, and recorded at the University of North Carolina. Lecture topics were: \#1: 
Knowledge of Pulp Morphology and Internal Anatomy; \#2: Access, negotiation, initial working length, crown down, final working length, apical enlargement and shaping errors; \#3: Endodontic radiography, interpretation, endodontic instruments; and \#4: Medicaments, filling and coronal seal. The study also contained a series of six narrated demonstration videos on a Maxillary Central Incisor: Access Demonstration, Canal Negotiation, Crown Down Preparation, Apical Preparation, Final Irrigation, and Final Obturation, which were recorded and edited professionally.

\section{Producing Videos and Recorded Lectures:}

All videos and recording lectures were created and edited by CEDI (Center for Educational Development and Informatics) at the University of North Carolina at Chapel Hill. Final Cut Pro Photoshop ${ }^{\circledR}$ was used to record and edit instructional videos. Final Cut Pro Photoshop, created by Apple ${ }^{\circledR}$, is a nonlinear editing system that allows users to edit video, photos, and audio in a single screen. Panopto ${ }^{\circledR}$ was used to record faculty lectures. Panopto is a software company that provides lecture recording, screen casting, video streaming, and video content management.

Once videos and lectures were completed, eight endodontic residents and five faculty members from the UNC Department of Endodontics were asked to provide feedback regarding the completeness and detail of the learning modules. Other faculty members from the UNC Departments of Prosthodontics and Radiology, as well as two faculty members from other departments at UNC and the University of Houston were consulted. After reviewing critiques and evaluation forms from these individuals, further improvements were made to all video demonstrations, and final approval was granted by the Preclinical Course Director. 


\section{Creating and Launching SAKAI Platforms:}

Two SAKAI ${ }^{\circledR}$ platforms were created for the course: one platform was for the traditional group and the other platform was for the blended learning group. SAKAI is an educational software platform used for teaching and research. Systems of this type are also known as Course Management Systems (CMS), Learning Management Systems (LMS), or Virtual Learning Environments (VLE).

The six narrated videos and the four lectures were uploaded to the UNC SAKAI platform. Only the blended learning group had access to these recorded resources.

The SAKAI platform for the blended learning Students contained the following components:

1. Links to reading assignments

2. Four interactive pre-recorded lectures pertaining to the content in PowerPoint using Panopto ${ }^{\circledR}$ covering the following topics:

a. Knowledge of Pulp Morphology and Internal Anatomy

b. Access and negotiation, initial working length, crown down and final working length, apical enlargement, shaping errors

c. Endodontic radiography and radiographic interpretation, endodontic instruments

d. Medicaments, filling and coronal seal

3. Two quizzes corresponding to the above lectures

4. Six narrated videos viewable using Final Cut Pro Photoshop software and organized in the following topics:

a. Access Demonstration 

b. Canal Negotiation
c. Crown Down Prep
d. Apical Preparation
e. Final Irrigation Protocol
f. Final Filling

The SAKAI preclinical course platform for the traditional group students contained the following components:

1. Links to reading assignments

2. Two quizzes corresponding to the traditional, live faculty lectures in the following topics:
a. Knowledge of Pulp Morphology and Internal Anatomy
b. Access and negotiation initial working length, crown down and final working length, apical enlargement, shaping errors
c. Endodontic radiography and radiographic interpretation, endodontic instruments
d. Medicaments, filling, coronal seal

\section{Application of the Study:}

The research study was explained to all eighty one students registered in the course DENT 220 Endodontics Preclinical Laboratory. The protocol for this research was reviewed and exempted by the Institutional Review Board for the Protection of Human Subjects (IRBPHS). Participation in the study was voluntary. The eighty one participants were randomly assigned to two groups: the first 41 students on the alphabetized class roster were assigned to the BL test group while the remaining 40 students on the roster were matched to the traditional test group. 
1. The traditional group: Students who learned using the conventional face-to-face learning $(\mathrm{n}=40)$ (Last name form M-Z)

2. Blended learning group: Students who were exposed to the blended learning methodology. $(\mathrm{n}=41)$ (Last name form A-M)

\section{Assessment Quizzes:}

All eighty one students were asked to participate in two written quizzes, a pre-assessment and post-assessment quiz. Pre-assessment quiz took place during the first introductory lecture which was attended by all students. The purpose was to assess the baseline knowledge of the two groups. Post-assessment quiz was presented in similar fashion to both traditional and BL groups after the completion of the completion of the laboratory exercise. The content of both quizzes were approved by the course program director. To eliminate testing contamination, students in the traditional group $(\mathrm{n}=40)$ did not have access to the SAKAI blended learning platform but did participate in the study:

Traditional group

a. Written pre-assessment quiz

b. Optional reading assignment

c. Live faculty lectures giving by an Endodontic faculty

d. Three laboratory hands-on exercises on Maxillary Endodontic Treatment, under direct faculty instruction, direction and supervision

e. Online post-assessment quiz 
Blended learning group

Students in the blended learning test group $(n=41)$ had password protected access to the online learning module on the same topics as the traditional group and participated in the following:

a. Pre-assessment quiz (written face-to-face)

b. Online reading assignment with PDF links

c. Narrated pre-recorded PowerPoint presentations using Panopto ${ }^{\circledR}$ containing individual password protection

d. Narrated demonstration videos of maxillary endodontic tooth access, instrumentation, irrigation and filling and Intra-orifice barrier placement. All videos were individually password protected.

e. Three sessions, three hours each of a hands-on laboratory by students, with limited faculty supervision

f. Online post-assessment quiz

All forty one students that were given access to the SAKAI blended learning platform had individually protected passwords. In addition to this protocol, records were maintained of how many times each of the students in this group launched the videos and the duration of each viewing session.

\section{Laboratory Exercises:}

During three laboratory exercises of the experiment corresponding groups were assigned to two different laboratories: 
1. Traditional Group: Students who learned using the conventional face-to-face format were placed in Laboratory 148 (first floor preclinical simulations laboratory) and received a traditional live narrated demonstration of the access, instrumentation, and filling a maxillary central incisor, all of which the students observed on their assigned lab bench monitors. This face-to-face demonstration took approximately 30 minutes prior to the student being permitted to perform the technique. Laboratory was staffed with 6 faculty members that were in charge of providing additional explanation of techniques in case student had additional questions.

2. Blended Learning: Students who were exposed to the blended learning methodology were placed in Laboratory 318 (third floor preclinical simulation laboratory). They were instructed to immediately begin accessing, instrumentation, and filling a maxillary central Incisor. Since this group had prior access to the videos, no live narrated demonstration was given. Ear pods or head phones were used by the students in the laboratory setting. Students were able to work independently by following the directions and demonstration in the videos. This laboratory session had limited amount of faculty and had an additional 30 minutes of practice since this group didn't need a demonstration by faculty.

In both groups, faculty members were present in the laboratory to answer students' questions and evaluate performance. The student/faculty ratio was 10:1 for both groups. However, in the blended learning group, faculty assistance was limited and had no presence of expert faculty but student/faculty ratio of 10:1 was maintained. In order to measure this limited assistance for the blended learning group, all faculty members had a custom table that allowed them to record the number of interactions and types of questions asked. The questions were classified as either 
Simple or Complex. Simple questions were related to technical procedures that took the faculty less than a minute to address or were necessary check steps. Complex questions were questions that required additional one-on-one demonstrations to comprehend the knowledge.

\section{Quizzes:}

For the two post-assessment quizzes, all students were present in their corresponding laboratory, Laboratories \#148 and \#347. The quizzes were uploaded to the SAKAI platform for both groups, password protected, and had a record specifying the log in time and date. Fifteen (15) minutes after initial quiz launching, quizzes from both groups were retrieved from the platform and students were no longer granted access. The content of both quizzes was identical for both groups and contained the same content as the pre-assessment quizzes. The only difference between the pre-assessment and post-assessment quizzes was the order of the questions and the randomization of the answers. The results for both groups for the pre- and post- assessment quizzes were statistically compared with ANCOVA.

\section{Manual Skill Grading:}

Once all three laboratory sessions were completed, all maxillary central incisors typodont teeth from both groups were collected for grading and all students were dismissed from their corresponding laboratory. At the end of the experiment, students who had difficulty learning to perform the skills were tutored until they mastered the technique, regardless of which group they had been a member of. All students were given access to the SAKAI blended learning platform in case they needed to review specific items of the technique. 
The eighty one plastic maxillary incisors typodont teeth were labeled, coded, and mixed in a single container so that the graders did not know the name of the student or his or her assigned group.

Eight endodontic resident members determined the total number of error points based on a set of pre-specified criteria. Each resident was calibrated and masked to the identity of each group. CITA (Council of Interstate Testing Agencies, Inc.) performance criteria were used to evaluate the endodontic treatment on the maxillary tooth.

A score of seventy-five (75) points or greater out of a maximum of 100 points was required to successfully complete the endodontic treatment on a maxillary central incisor. Deficiencies were categorized into minor, major, and critical deficiencies:

a. Minor Deficiencies: Each confirmed minor deficiency resulted in a sixteen (16) point deduction.

b. Major Deficiencies: Each confirmed major deficiency resulted in a twenty-four (24) point deduction.

c. Critical Errors: Critical errors were deficiencies that would lead to patient injury in a clinical setting or would jeopardize the prognosis of the treatment, and such errors were given special consideration by the graders. The following criteria were considered critical errors in the maxillary central incisor endodontic treatment:

- Wrong tooth/surface treated

- The crown or root was fractured during instrumentation or obturation

- The crown of the tooth had been reduced on occlusal surface

- There was evidence of gross damage and/or alteration to either opposing or adjacent hard/soft tissues 
- There was significant evidence of damage to the facial shroud

- There was restorative material in the pulp chamber

- A file was separated in the root canal which prevents the obturation of the root canal system

- A perforation was present in any portion of the tooth

- The canal was not filled or is filled with non-approved examination material

Any confirmed critical error resulted in a score of zero for that procedure, even though other criteria within that procedure or part may have been rated as satisfactory. See Table \#1.

Unpaired t-tests were used to determine whether there was a statistically significant difference between the traditional and blended learning test groups in the endodontic simulated exercise.

\section{Surveys:}

Eighty one students were surveyed after the completing the premolar exercise, allowing the blended learning group the opportunity to participate in the traditional methodology and the traditional group the opportunity to access the online material.

Two sets of surveys were developed for the traditional and blended learning test groups, respectively. The surveys were developed using the online software Qualtrics. The eighteenquestion survey included both multiple choice and open-ended questions. The students' learning experiences were evaluated by assessing students' perceptions of their learning experiences, the assessment of their skill levels, and their confidence in performing the skills taught. Students' perceptions regarding the recorded seminar, the reading materials, the technology, and the post seminar discussions were measured on a 5-point Likert scale (1=strongly disagree and $5=$ 
strongly agree). The surveys were developed through consultation with the Department of Education at UNC based on previously published research and feedback received from thesis committee advisors.

An e-mail was sent to all eighty one students through Qualtrics, an online distribution software program. To encourage feedback, e-mail addresses were not linked with individual responses, and participants were awarded 3 percentage points on their final grade for the preclinical course. The deadline for completion of the surveys was set approximately three weeks following the date of the first e-mail. A second e-mail reminder was sent out two weeks after the first email. Data were collected from Qualtrics and imported into an Excel spreadsheet for analysis. Descriptive statistics such as percentages, means, and standard deviations were used to analyze findings.

\section{RESULTS}

There were eighty one students in the study. Forty were in the traditional test group and forty one were in the blended learning test group. The outcomes measured were the students' ability to complete a maxillary anterior endodontic treatment in an acrylic simulation maxillary central incisor, and the scores obtained by the students in pre- and post-assessment quizzes.

Pre-assessment and Post-assessment Quizzes: Analysis of Covariance, ANCOVA, was used to compare the post-assessment quiz scores using the pre-assessment quiz score as a covariate, and included interaction between the traditional and BL test groups. The level of significance was set at 0.05 . The mean grades of the students from the pre-assessment quiz and postassessment quiz tests are shown in Figure 1. There was no statistically significant interaction in pre-assessment quiz scores between groups indicating that the pattern of pre-assessment quiz scores were similar for both groups and both groups were similarly distributed $(\mathrm{P}=0.59)$. After 
controlling for the pre-assessment quiz scores, there was no statistically significant difference in the post-assessment quiz score averages between the two test groups $(\mathrm{P}=0.92)$.

Manual Competency Exam: The mean grades of the students at the manual skill exercise (completion for a maxillary central incisor, access to filling) showed there was a significant difference in the mean exercise grade, which served as an indicator of the acquisition of manual dexterity $(\mathrm{P}=0.0067)$. On average, the $\mathrm{BL}$ group scored higher than the traditional group on the exercise ( $\mathrm{x}=42.5, \mathrm{~s}=14.4$ vs. $\mathrm{x}=34.2, \mathrm{~s}=12.1$, respectively) Figure 2 .

Survey: All eighty one students (100\%) participated in the survey. Survey results demonstrated that a high percentage of students learned appropriately, were attentive, and comprehended the videos sufficiently to complete the simulated exercise. Students' perceptions of the learning experience are graphically represented in Figures 2, 3, 4, and 5. Almost all students responded positively when asked if they had liked the blended learning techniques.

Skills Demonstration: Regarding learning a clinical skill, such as performing a root canal, a higher percentage of students in the BL group (61\%) showed a preference for their method of learning than did the students in the traditional group, of whom $42 \%$ showed a preference for the traditional method of learning. $68 \%$ of the BL group agreed that this method helped them learn the content, versus $38 \%$ in the traditional group. Both the $\mathrm{BL}$ and traditional groups reported a similar high level of attentiveness ( $85 \%$ and $74 \%$, respectively) while participating in their learning method. However, some students in the traditional group said that the ability to remain attentive in a large lab varied greatly depending on where the student sat (front of lab versus back) (Figure 2).

Lectures: The traditional group attended a traditional lecture given by a live faculty member, while the blended learning group watched a pre-recorded lecture on Panopto®. Participants in 
the BL group reported a much higher level of attentiveness during lectures $(81 \%)$ than did the traditional group (27\%). This can be attributed to the BL group students' ability to rewind or fast-forward the lecture, pause and take notes, and choose a preferred time to watch the video lecture. Both groups were almost identical in responding that the use of technology was not a distraction: $18 \%$ of the traditional group agreed the use of technology was a distraction while $19 \%$ of the BL group said the same. Although a majority in both groups reported a high level of satisfaction with their respective method of receiving lectures, the BL group reported a slightly higher level of satisfaction (75\%) than did the traditional group (56\%). However, several students in the BL group complained that they could not receive immediate answers to their questions during a lecture; during or after watching online videos, BL group students had to submit questions to an online forum and wait hours or days for a response, whereas traditional students could simply ask the faculty during or immediately after the lecture (Figure 3).

Confidence in Performing RCT: Majority of both groups felt confident in their ability to perform a root canal treatment upon completion of their respective teaching methods: traditional group $=59 \%$ vs. BL group $=66 \%$. However, a higher percentage of both groups felt that they would require additional faculty help in performing an RCT; 77\% of the traditional group vs. $71 \%$ of the BL group reported that they would require additional faculty help. (Figure 4) Both groups asked roughly the same number of questions in the laboratories; however, it was noted that many of questions from the traditional group were more basic in nature than the BL group. Typical examples of the questions asked by the traditional group include: "How many accessory cones should I place?", "Which instrument should I use?", or, "Is my access too big? Too small?" Meanwhile, the BL group questions were more related to conceptual definitions such as AGF (Apical Gauge File) vs. MAF (Master Apical File). (Table\#3) 
Satisfaction of the BL Group: The blended learning group reported a markedly higher level of satisfaction: $85 \%$ of the participants in the BL group said that they would like to have subsequent seminars taught using this method. In addition, $85 \%$ of the same group of students said that they would recommend this learning method to other students taking the same course. However, it should be noted that many students commented that, although they preferred viewing lectures and skills demonstrations using the online method, they also said it was imperative to have faculty in the lab to allow for direct interaction. (Figure 5)

\section{DISCUSSION}

Educational effectiveness in dentistry is correlated with a strong student academic performance, accomplishment of course objectives, development of manual skills and a high level of student satisfaction reflected in a positive course evaluation. It is believed that the accomplishment of these factors creates a constructive and enriched learning environment that ensures the successful transfer of knowledge. Educational research has found that blended learning can provide the right mixture of synchronous conversations and asynchronous interactions to create an effective and strong learning environment. ${ }^{28,29,30,31,32}$

In the present study, the educational effectiveness was assessed and tested using three major components: (1) Acquisition of knowledge: through the students' academic performance on quizzes; (2) Gain of dexterity and ability: through the measuring of students' manual skills based on the completion of a RCT using a resin maxillary central incisor; and (3) Course satisfaction: gauged by asking students to complete post course surveys. Both knowledge and skills assessments came from their grades. The students' satisfaction levels with the course were derived from the surveys. This methodology has been used similarly in other studies. $33,34,35$ 
The majority of BL research has concentrated its efforts to demonstrate how the gain of conceptual knowledge can be the same or better compared to distance learning and traditional classroom instruction. In dentistry, BL has been tested in the areas of orthodontics and prosthodontics where it has been shown that learning via a virtual interactive asynchronous environment can be significantly improved with the presence of a tutor. However, very little has been done in the area of acquiring manual skills, particularly in Endodontics and especially in a preclinical undergraduate course.

Regarding students' performance, it was determined that a statistically significant difference existed when comparing the mean grades of the competency practical test (anterior RCT) between the traditional and the BL test groups. The results indicated that the students of the $\mathrm{BL}$ group performed better than the students assigned to the traditional group. Regarding the pre and post-assessment quizzes, using the pre-assessment quiz score as a covariate, there was no statistically significant difference between the two test groups based on the average postassessment quiz scores.

Although a great deal of evidence exists showing no significant differences in student performance between distance learning and traditional classroom instruction, there remains significant differences in the way online learning experiences are perceived by the participating students. Multiple studies have shown that students from BL courses demonstrate increased content retention resulting in improved acquisition of knowledge, skills, and attitudes because they have control over the content. ${ }^{36}$ Since students in BL group had limited contact with faculty, it is believe that some of the dynamics and interaction that come with synchronous (faceto-face) teaching is lost, which could possibly explain why the BL group did not outperform the traditional group on the post-assessment quiz. 
The BL group in this study reported a markedly high level of satisfaction with the blended learning techniques: $85 \%$ of the participants in the BL group said that they would like to have subsequent seminars taught using the BL method. In addition, $85 \%$ of the same group of students said that they would recommend the BL learning method to other students taking the same course. However, it should be noted that many students commented that, although they preferred viewing lectures and skills demonstrations using the online method, they also said it was imperative to have faculty in the laboratory to allow for direct interaction. This may indicate that students and faculty do not see BL as replacing traditional instructor-led training, but as a complement to $\mathrm{it}^{17}$, especially in regards to skills training since the students perform the skills themselves in the laboratory.

The student satisfaction of the course was notably high at $85 \%$, based on students' answers to the survey. In particular, students from both groups remarked on the high quality of the videos, lectures, organization of the course, and the educational content material. This can be explained because the organization of the BL course content was developed to mirror similar distance learning principles and to enhance student self-paced learning. In addition to this effort, the course material was developed by professionals in the area specifically for this course. Therefore, the material did not resemble any existing, outdated written or electronic material created in the past.

The quality of the E-learning material and positive students' evaluations are important factors in determining the success of blended learning courses in higher education, and dentistry in particular. Studies completed by Tan et al. ${ }^{37}$, in radiology, Linjawi in orthodontics ${ }^{38}$ and Gibbard in prosthodontics ${ }^{39}$, where traditional courses were converted into an E-learning course, 
confirmed, based on students' positive responses and the quality of the content, that the Elearning course versions could be fully implemented into the curriculum.

Technological challenges can be very frustrating for learners and can negatively impact the perception of electronic learning materials. ${ }^{40}$ Students in this pre-clinical Endodontics BL study strongly agreed they were not distracted from learning because of the technology. However, to truly advance online distance education then maximum efforts need to be placed on reducing technological difficulties. In previous studies done in the Orthodontic department at UNC, technological issues were the most frequent criticism. ${ }^{40,14,35,21}$ Residents and faculty were most concerned with the need for better editing, the need for more frequent visual aids, the slow pace of the seminars, and video/sound quality. The high satisfaction rate with the BL approach in this study was due mainly to the quality of editing, visual aids, detailed instruction, and the sound of the online material.

Nowadays, the faculty of UNC-school of dentistry is fortunate to have the Center for Educational Development and Informatics (CEDI), where the professionals at the center provide faculty with support and knowledge for making videos, recording lectures, and creating platforms using state-of-the-art technology and equipment not present in other dental schools. For example, Panopto ${ }^{\circledR}$ is a program that allows for multiple windows to be viewed simultaneously. This allows the viewer to observe both the presenter and the presentation at the same time, with the added ability to pause, skip, and rewind. The high definition of the videos, fabricated with Final Cut Pro Photoshop, as well as the clear sound contributed to the high level of satisfaction from the students.

The students also reported being more attentive during the online lectures since they were able to pause and write notes throughout the lectures, to avoid missing any part of the 
lecture. They could also re-watch part of the videos around their personal schedules and at their own pace. One student reported that, "it prevents me from losing focus and surfing the internet as I would in class." Another student with a learning disability and short attention span thought, "I can pause the video and refocus and begin again when I am ready. I am also in a more comfortable environment without distractions [from] other classmates." Another student thought that the online video, "levels the playing field: everyone learns the same material and reviews it as much as necessary. When faculty lecture or demonstrate in the lab, not everyone can see or hear equally, and different faculty members share different pieces of information."

The face-to-face meetings in the laboratories were rated as highly important by most of the students. There is still a high preference for visible communication with the teacher and social interaction with colleagues. Previous studies reported that students generally have a positive response to web-based instructional formats, but that classroom interaction and participation are still perceived as a necessary component to learning. ${ }^{41}$ Students prefer that online modules are used as a complement to learning. ${ }^{42}$

During this study, the most reported disadvantage in the open-ended questions survey, using the BL methods versus traditional faculty instruction, was the ability to ask questions and receive immediate feedback while using an online teaching tool. Even though a forum was provided to post questions, only a few students used this feature in the SAKAI platform. Instead, students preferred asking the faculty directly during the laboratories and/or e-mailing the faculties directly. As one student stated, "SAKAI takes too many clicks to get to the forums and it may be easier to ask a nearby faculty. The problem with online interaction is sometimes faculty may not be as readily accessible as one would like." This represents a problem and disadvantage since the BL students could miss out on the potential learning opportunities offered 
through other students' questions. On the other hand, some students reported that when the faculty was asked a question, the faculty tended to lose track of the lecture, thus inadvertently adding confusion.

According to Klein's study, ${ }^{40}$ the discussion format is the most effective way of learning the material, but at the same time, it is not the most time-efficient. There is a lot of dead-time or empty pauses in a discussion while people think about what they want to say. Also, lectures that are not rehearsed, according to the authors, can potentially negatively affect their acceptance. On the other hand, in our study many faculty members and residents thought that having residents participate in the video of the recorded seminars would be beneficial. It was agreed that it would have been more interesting and could have provided a better learning experience to watch the interaction between the residents and faculty in the recorded seminar video as opposed to seeing the faculty member lecture alone. However, the lectures were rehearsed and recorded in a nonnoise environment to improve the audio-visual experience. As a result, a majority of the students still reported being satisfied with the short and concise lectures despite having only a single faculty member narrating the videos.

It cannot be expected that the current generation, "Millennials", will learn in the same way that previous generations did. The members of the Millennial Generation, or Generation-Y, were born between 1980 and 2000. Millennials comprise nearly a quarter of the world population. They're the first generation to grow up surrounded by digital media; two thirds of them used computers before the age of five. They are constantly connected to friends, parents, information, and entertainment. Accustomed to being surrounded by technology that offers much potential, they have high expectations and clear goals. They are willing to work hard, and expect to have the support they need to achieve their objectives. Millennials are multi-taskers and can 
easily engage in a multitude of activities at the same time, such as text messages, email, blogs, and interpersonal dialogue. ${ }^{43}$ They comprise the current and next generation of dental students that educational institutions have to adapt their curriculums for in order to have success molding them into future dentists. Therefore, blended learning methods can ameliorate the challenge of keeping up with this paradigm shift in curriculums since the techniques are more in line with the educational needs of the students of today.

\section{Application to future Endodontic Education:}

With increasing teaching demands of many endodontic faculties in this country and the need to better integrate and decompress our dental curriculum, BL is an option that can be implemented in many programs at undergraduate and graduate levels to help with these issues. Although distance education cannot be expected to completely replace traditional classroom instruction, this study confirms that BL can be a useful complement. In some cases, BL proves it can be a replacement for traditional education since data collected clearly states that it is at least as good as the traditional approach. It appears that BL is particularly beneficial and useful in teaching the basic concepts that underlie clinical practice in a pre-clinical setting. According to Bednar's study, ${ }^{44}$ there are two benefits BL learning can offer. It alleviates problems associated with the decreasing numbers of experienced full-time faculty in our institutions and it reduces the dependence on expert faculty to make demonstrations during the laboratory sessions by allowing junior faculty to take a leading role teaching intensive preclinical courses. For example, in many instances, high quality narrated presentations and videos can be moderated by junior faculty during laboratory session even if expert faculty is not available

It seems highly likely that these benefits would also broadly impact other areas of graduate and postgraduate dental education as well as continuing dental education. 


\section{CONCLUSIONS}

A blended learning methodology for teaching Endodontics to undergraduate dental students was evaluated in the present study, and findings supported that it is viable to teach the pre-clinical undergraduate Endodontics course using this method. The BL approach was well received by the dental students with no major problems or issues. Concerning student performance, students in the blended learning group performed significantly better on the manual skills assessments and similarly for the conceptual knowledge compared to their colleagues in the traditional group. With the utilization of the blended learning environment, students were able to learn and demonstrate the dental procedure taught with a $30 \%$ reduction in lecture time.

Students also evaluated the course components in a positive way: the content, organization, educational material, and design were highly appreciated by students in both groups. Students' attitudes towards blended learning courses were positive: they think that blended learning is effective and motivating; it promotes active engagement and enhances selfstudy and self-assessment. Particularly, students in the blended learning group liked the combination of on-line and face-to-face teaching in the laboratories. The blended approach towards learning was judged to be effective and enjoyable. Students did not see this approach to learning as replacing traditional instructor-led training, but as a complement to it.

\section{Suggestions for Implementation of Blended Learning in Dental Schools:}

Implementation of BL requires a good and clear plan, and to be successful not only depends on the instructors directly involved but also on administrative members of the institution. Just as a traditional face-to-face instructional environment relies on the faculty, technology, registrar, academic advising, and enrollment services, just to name a few, so does a 
BL environment. The plan described below outlines an overview of components that should be considered and addressed during the implementation phase of a new instructional delivery mode.

\section{Institutional Planning}

If the teaching institution wants to consider blended learning as a learning method it is important to see if it is a good fit with its character and teaching mission; therefore, the institution must have a clear and articulated mission. If it is not, the strategic plan for successful integration of BL will not mesh with the character and mission of the institution.

\section{Technology Planning}

A teaching institution considering to implement BL needs to have a current and up-todate technological infrastructure to do it. First, they must provide easy access to a secure Wi-Fi with servers capable of handling large amounts of data. Second, they must own a course management system (CMS) such as Blackboard or SAKAI. Third, they need to provide computers to their learners that easily connect to their system. Lastly, they need to have an personnel dedicated to providing computer and informatics support, as well as audio visual production assistance. For example, at UNC-CH School of Dentistry, all dental graduate and undergraduate students are required to purchase a computer before enrollment. These computers have password-secure access to school servers inside or outside the campus which are set up by the OCIS office (Office of Computer and Informatics office) and CEDI (Center for Educational Development and Informatics).

\section{Marketing Inside the Schools and Faculty Support:}

Before this project was initiated, the project was explained to the Chair of the Department of Endodontics, and Director of the Endodontic Laboratory. All instructors needed to be on 
board with the project and willing to provide their PowerPoint presentations and record their lectures on Panopto. A big part of this acceptance depended on the results of the pilot studies and the results of previous research studies at other universities. It is imperative that faculty have an interest in pursuing blended learning as an instructional delivery method and demonstrate a commitment to supporting the design and preparation of blended learning techniques.

\section{Learner Support}

How students taking blended courses are supported is important. Regular meetings to go over students questions before the laboratory can be very helpful and less demanding than an around-the-clock support desk or residents on call during the Online Lecture. Another alternative can be to provide tutoring and advising which can be scheduled at various hours and available online.

\section{Blended Learning Faculty Development Implementation}

As it can be inferred from above, a critical component of a successful blended learning initiative involves an effective and efficient faculty development program. At UNC, faculties have much support from OCIs and CEDI; however, we will need a central program means that you implement an offering that is coordinated and integrated with the blended initiative. In other words, a process in place that will lead to or culminates teaching in a blended environment - as opposed to an uncoordinated, disjointed effort where instructors might or might not participate in development and support opportunities. A coordinated program has a greater likelihood of producing efficiencies and positive outcomes, such as discipline-based communities to support blended learning, an ongoing dialogue of experiences related to successful blended learning, peer evaluation processes, and coordinated support among others. 
In this study we selected four of the twelve lectures offered in the Dent 220 class and then met with the corresponding faculty and guided them through the process of recording and uploading the material to the SAKAI platforms.

\section{Potential Implementation Costs}

Not surprisingly, a successful blended learning program might have several associated costs. Below is a suggested list of what some of those costs might include, which will vary depending on the institution's experience with blended and online learning and on its implementation preferences.

\section{- Instructors}

Course redesign time

Release time from some courses during pilot semester

Orienting to model and development of courses

Course redesign resources

\section{- Media specialists}

Instructional designers

Instructional technologists

Information technology

\section{- Infrastructure}

Labs

Wireless capabilities

Software

Help desk 


\section{- Student success}

Determining and supporting readiness

Advising

Orientation

Online services (i.e., tutoring, advising, library)

\section{Disadvantages of Blended Learning:}

According to Seidei, ${ }^{45} \mathrm{BL}$ can provide with the following disadvantages:

1. Detailed and extensive preparation work from design to delivery. This is a long process that needs to be initiated before the course starts.

2. Limited contact between lecturer and students create loss of the dynamism that comes with face-to-face interaction.

3. Preparation of the handouts of the lecture for students who often prefer a printout rather than the online version. Educational materials developed by the lecturers simply may not be the same set when used for online dissemination and lecture handout. They have to be reformatted so that they guide the students through a process of independent study when they are not in a face-to-face session. This additional task required of the lecturers is yet to be appreciated for what it is worth.

4. Students sometimes feel that they are given more work to do when distance modalities are used.

\section{Challenges}


Dental schools can face many challenges in implementing BL curriculum, from rethinking course design and adopting a new approach to teaching. In addition to the technological challenges, instructors need to learn how convert their traditional instruction to facilitate online discussions and re-examine traditional methods of assessment of student work to take into account the new learning environment. Managing the dual learning environment (the BL hybrid environment) also adds additional scheduling and communication challenges as courses meet both online and face-to-face. Instructors must also take care not to overload themselves and their students. Instructors must be prepared to help students understand their active role in the $\mathrm{BL}$ and assist students in keeping their work on time and on track, and be prepared to offer strategies for trouble-shooting new course technologies.

Regarding technological challenges, at UNC's dental school, the resources to develop online learning modules are readily available. Other schools that don't have these resources can use the produced educational material via email, or the American Association of Endodontics website or even the UNC school website. Per previous studies done here at UNC, orthodontic programs from other institutions were invited to use the educational material via email for free. Later on, schools were able to use the educational seminars through the AAO American association of Orthodontics for a fee. Also a $\$ 150$ dollars fee was charged for the video conferences with a faculty member.

The development of a library of recorded seminars produced by multiple institutions is the current goal of the AAO-supported project. In Klein's study, ${ }^{40} 70 \%$ of the participants reported that they wanted to use the seminars in preparation for the board examination. At UNC all the resources are available to produce high quality online learning modules. The bottom line 
is now we know that BL can be successfully integrated into preclinical courses, it is time for us to share with other schools and educational institutions how this teaching method can be implemented.

\section{Suggestions for Future Studies:}

There needs to be an implementation of small group discussions of faculty and residents which answer student questions and comments. These sessions could be recorded and placed in a platform as a separate item for future courses, as the questions tend to be repeated by new students in the same courses each semester. 


\section{Appendix I}

\section{Tables}

Table \#1: Criteria were used to evaluate the endodontic treatment on the maxillary tooth.

\begin{tabular}{|lr|}
\hline \multicolumn{1}{|c|}{ Endodontic Examination } & Score \\
\hline No errors & 100 \\
\hline 1 confirmed deficiency & 84 \\
\hline 1 confirmed major deficiency error & 76 \\
\hline 2 confirmed minor deficiencies & 68 \\
\hline 1 confirmed major deficiency: !confirmed minor deficiency & 60 \\
\hline Any confirmed critical error & 0 \\
\hline
\end{tabular}


Table \#2: CITA scoring guide.

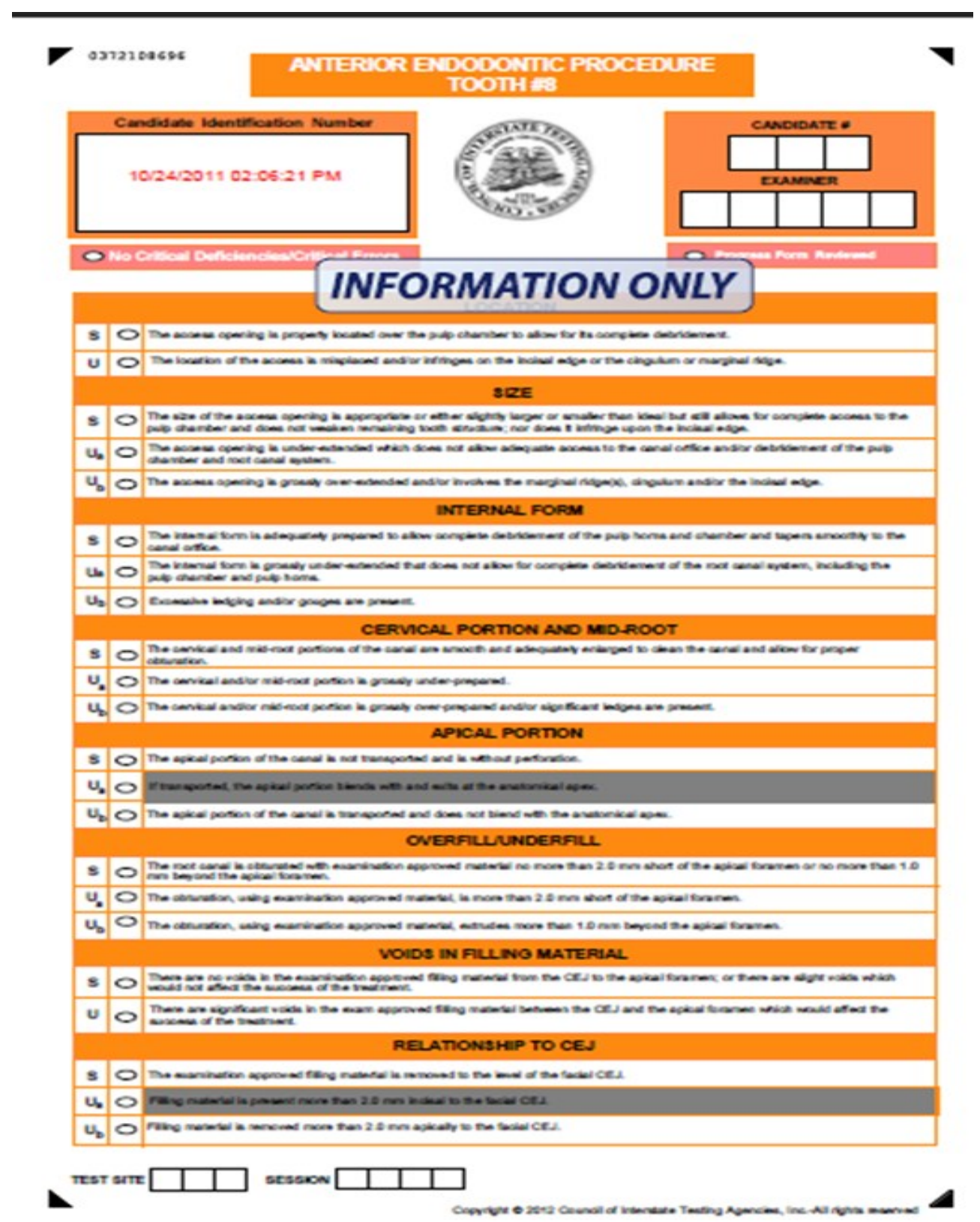


Table \#3: Summary of Questions.

\begin{tabular}{|c|c|c|c|c|c|}
\hline \multicolumn{6}{|r|}{ ONLINE } \\
\hline Faculty & $\begin{array}{l}\text { Simples } \\
\mathbf{Q}\end{array}$ & $\begin{array}{c}\text { Complex } \\
\mathbf{Q}\end{array}$ & $\begin{array}{l}\text { Check } \\
\text { Steps }\end{array}$ & Total & Comments \\
\hline Z & 10 & 0 & 0 & 10 & \\
\hline $\mathrm{R}$ & 1 & 1 & 3 & 5 & working length \\
\hline M & 2 & 0 & 6 & 8 & how to work the spreader force \\
\hline $\mathrm{L}$ & 27 & 1 & 11 & 39 & Def. of AGF Vs. MAF, Level of sear! \\
\hline $\mathrm{R}$ & 3 & 0 & 29 & 32 & How is looking so far, how to ensure smooth access \\
\hline C & 7 & 0 & 8 & 15 & \\
\hline $\mathrm{R}$ & 8 & 7 & 18 & 33 & \\
\hline C & 22 & 0 & 9 & 31 & \\
\hline M & 2 & 7 & 19 & 28 & $\begin{array}{l}\text { Remove lingual shelf, just to look at the prep, brushing actions, one broken file in } \\
\text { one student, did not know whit to work file. }\end{array}$ \\
\hline Z & 0 & 0 & 19 & 19 & Endo Z bur \\
\hline TOTAL & 82 & 16 & 122 & 220 & \\
\hline \multicolumn{6}{|c|}{ TRADITIONAL } \\
\hline Faculty & $\begin{array}{c}\text { Simples } \\
\mathbf{Q}\end{array}$ & $\begin{array}{c}\text { Complex } \\
\text { Q }\end{array}$ & $\begin{array}{l}\text { Check } \\
\text { Steps }\end{array}$ & Total & Comments \\
\hline $\mathrm{H}$ & 9 & 6 & 8 & 23 & lingual shelf \\
\hline G & 17 & 1 & 6 & 24 & Access extends \\
\hline D & 2 & 0 & 30 & 32 & What bur should I use to de roof? \\
\hline G & 2 & 0 & 3 & 5 & What to do when block by debriefs? \\
\hline $\mathrm{H}$ & 20 & 4 & 2 & 26 & $\begin{array}{l}\text { All questions about de roofing and removing pulp } \\
\text { horns/what burs to use to do access }\end{array}$ \\
\hline $\mathrm{H}$ & 2 & 0 & 6 & 8 & Size of access and bur \#4 to access Vs. another ones. \\
\hline $\mathrm{B}$ & 10 & 5 & 13 & 28 & How do I know when I had placed enough accessory cones. \\
\hline $\mathrm{H}$ & 7 & 0 & 15 & 22 & $\begin{array}{l}\text { how do you get sealer down the canal, how do I know } \\
\text { what cone to use, how many accessories, how hard to } \\
\text { push with the Spreader, best way to get sealer out the } \\
\text { chamber, how low should I sear. }\end{array}$ \\
\hline K & 23 & 0 & 21 & 44 & $\begin{array}{l}\text { Students were not aware that they needed tp place more } \\
\text { than one accessory cones. }\end{array}$ \\
\hline $\mathrm{H}$ & 1 & 2 & 30 & 33 & \\
\hline TOTAL & 93 & 18 & 134 & 245 & \\
\hline
\end{tabular}




\section{Appendix II}

\section{Figures}

Figure \#1: Mean and Box Plot of grades for the knowledge pre-quiz and post-quiz scores

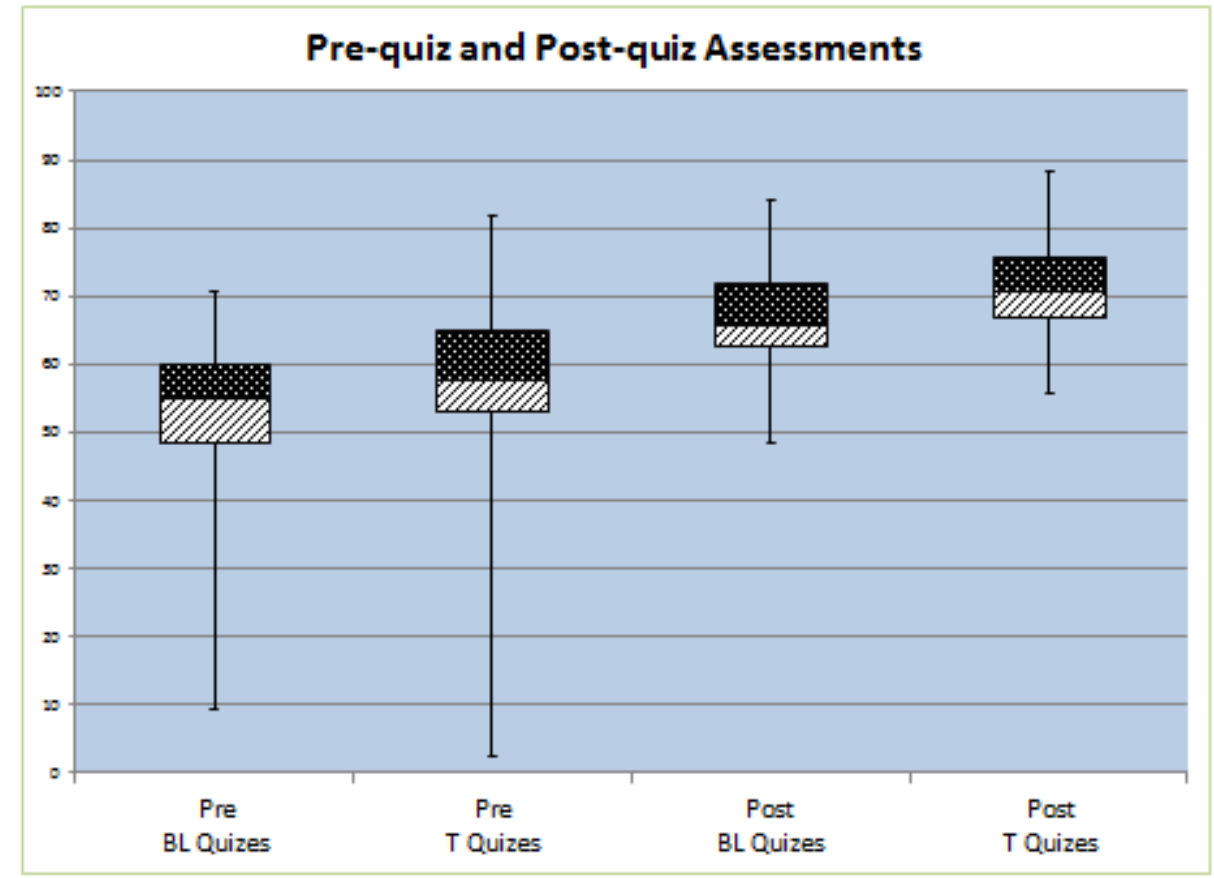

\begin{tabular}{|llll|}
\hline & Minor Std & Mean & Mean + Std \\
Pre Quiz BL & 41 & 53 & 65 \\
Pre Quiz Tr. & 45 & 58 & 70 \\
Post Q BL & 58 & 66 & 75 \\
Post Quiz Tr. & 65 & 72 & 79 \\
\hline
\end{tabular}


Figure \#2: Manual Skills RCT Competency Results: Averages and Standard Error

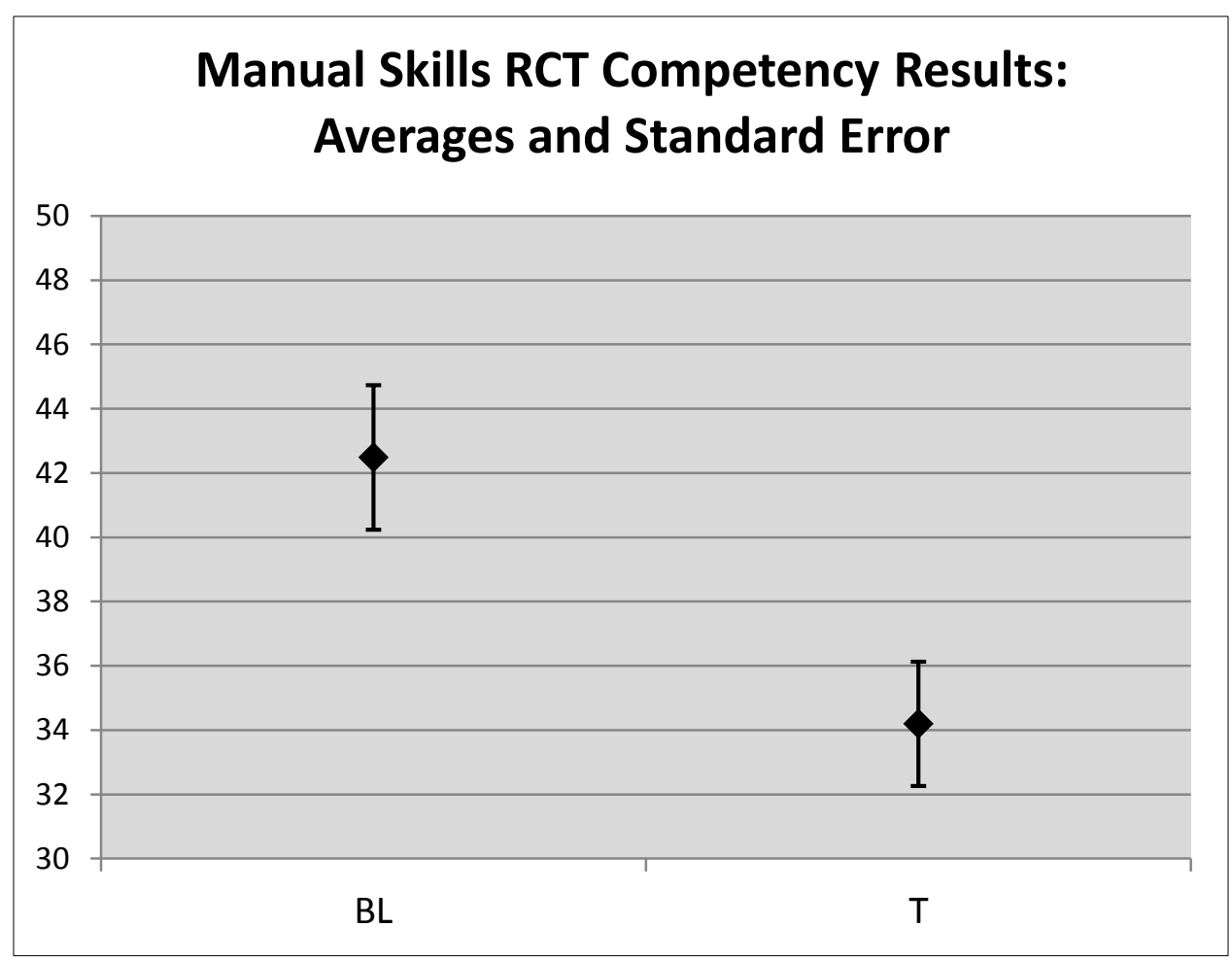


Figure \#3: Skills Demonstration

Clinical Skills : BL Vs. Traditional

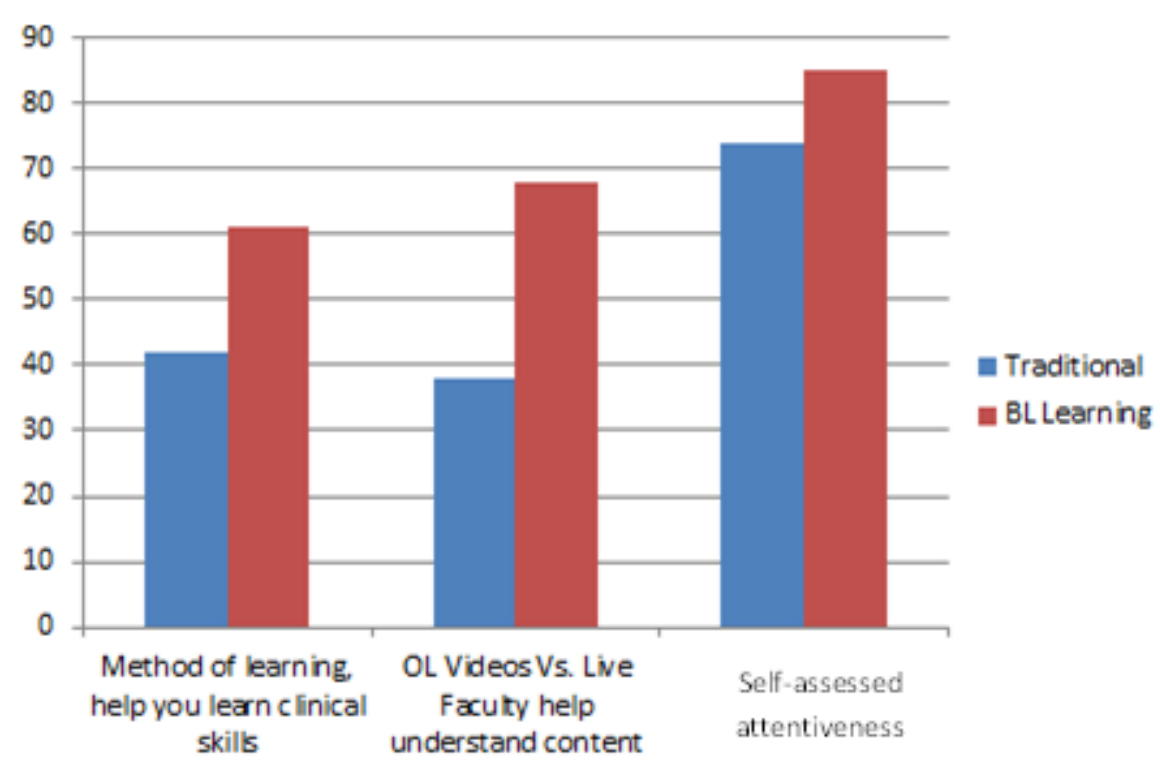


Figure \#4: Lectures

Lectures: BL Vs. Traditional

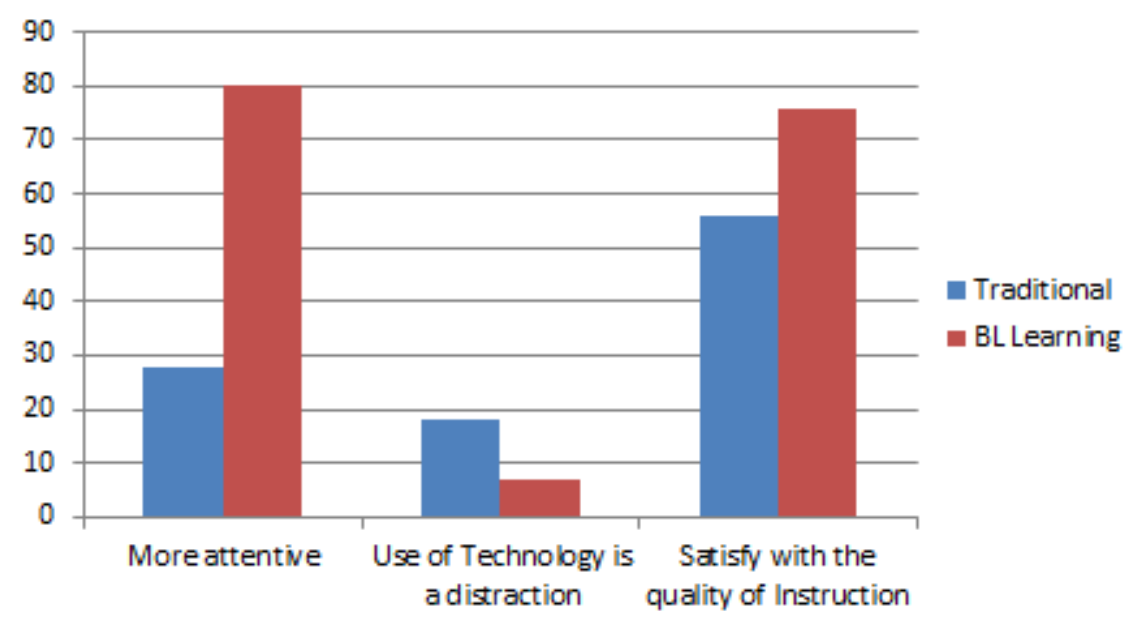


Figure \#5: Confidence in Performing RCT

\section{Confidence in Performing RCT: BL Vs. Traditional}

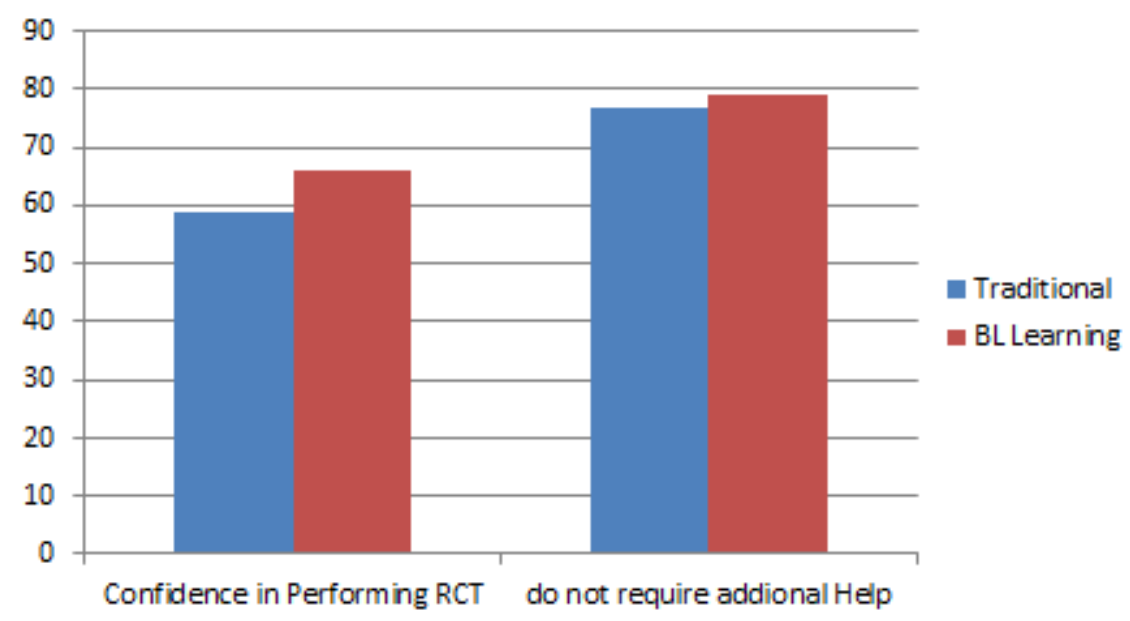


Figure \#6: Satisfaction of the BL Group

\section{Satisfactions: BL}

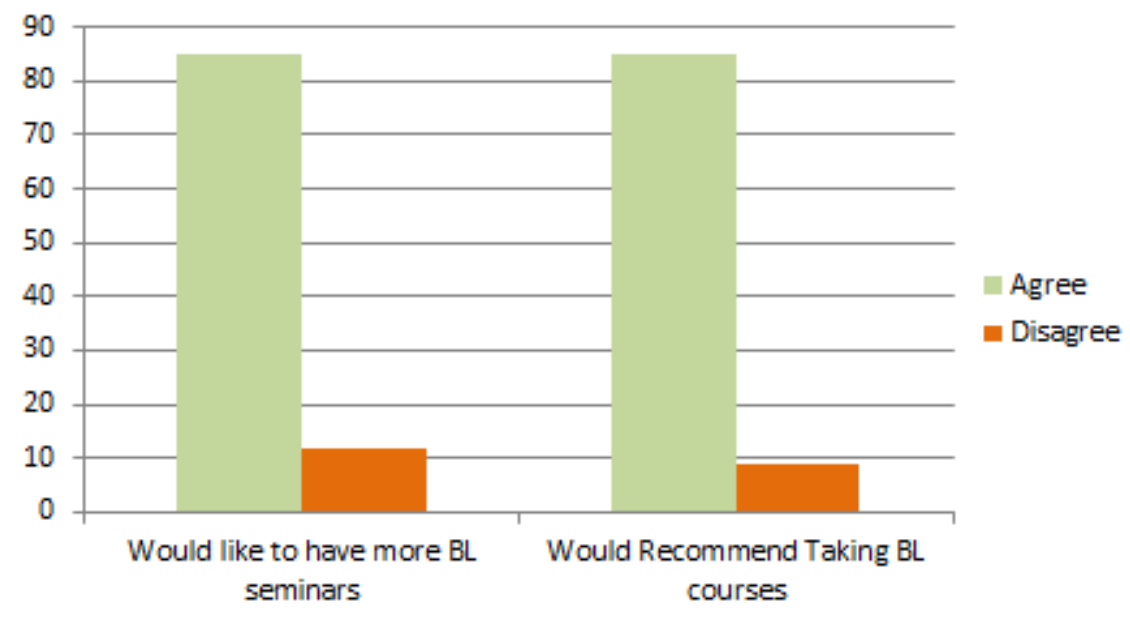




\section{References Cited}

${ }^{1}$ Graham, C. R. Blended learning systems: Definition, current trends, and future directions. Handbook of blended learning: Global perspectives, local designs. San Francisco, CA: Pfeiffer. $2005 ; 3-21$.

${ }^{2}$ Cornell R. The onrush of technology in education: the professor's new dilemma. Educ Technol 1999; 39(3): 60-3.

${ }^{3}$ Garrison DR, Kanuka H. Blended learning: uncovering its transformative potential in higher education. Internet Higher Educ 2004; 7:95-105.

${ }^{4}$ Fitzgerald WF. The instructional use of computers in dental education. Comput Biol Med 1973; 3:307-18.

${ }^{5}$ Mast RA, Watson JJ. Dental learning resources center. J Dent Educ 1976; 40:797-9.

${ }^{6}$ Stephens C, Grigg P. A computer-based orthodontic learning package: report of a trial. Dent Update 1994; 21:64-8.

${ }^{7}$ Vullo RP, Eisner J. DentLE - the dental learning environment: a prototype demonstration. Proc Annu Symp Comput Appl Med Care 1992:800-1.

${ }^{8}$ Irvine NR, Moore RN. Computer-assisted instruction in mixed dentition analysis. J Dent Educ $1986 ; 50: 312-5$.

${ }^{9}$ Demirjian A, David B. Learning medical and dental sciences through interactive multi- media. Medinfo 1995; 8(Pt 2):1705.

${ }^{10}$ Grigg P, Stephens CD. Computer-assisted learning in dentistry: a view from the UK. J Dent $1998 ; 26: 387-95$

${ }^{11}$ Lechner SK, Thomas GA, Bradshaw M. Interactive computer teaching/learning in the dental curriculum: partial denture design. Aust Prosthod J 1995; 9:21-6.

${ }^{12}$ Starr DR. Virtual education: current practices and future directions. Internet Higher Educ 1998; 1:157-65

${ }^{13}$ Johnson DW, Johnson RT, Smith KA. Active learning: cooperation in the college classroom. Edina, Minn: Interaction Book Co.; 1991.

${ }^{14}$ Bednar ED, Hannum WM, Firestone A, Silveira AM, Cox TD, Proffit, WR. Application of distance learning to interactive seminar instruction in orthodontic residency programs. J Orthod Dentofacial Orthop 2007; 132:586-94. 
${ }^{15}$ Cook DA, Levinson AJ, Garside S, Dupras DM, Erwin PJ, Montori VM. Internet-based learning in the health professions: a meta-analysis. J Am Med Assoc 2008; 300:1181-1196.

${ }^{16}$ Schmid RF, Bernard RM, Borokhovski E. Technology's effect on achievement in higher education: a Stage I meta-analysis of classroom applications. J Comput High Educ 2009; 21: 95109.

${ }^{17}$ Ruiz JG, Mintzer MJ, Leipzig RM. The impact of E-learning in medical education. Acad Med. 2006; 81:207-212.

${ }^{18}$ Johnson DW, Johnson RT, Smith KA. Active learning: cooperation in the college classroom. Edina, Minn: Interaction Book Co.; 1991.

${ }^{19}$ Allen M, Bourhis J, Burrell N, Mabry E. Comparing student satisfaction with distance education to traditional classrooms in higher education: a meta-analysis. The American Journal of Distance Education 2002: 16, 83-97.

${ }^{20}$ Zhang D. Interactive multimedia-based E-learning: a study of effectiveness. The American Journal of Distance Education 2005; 19: 149-162.

${ }^{21}$ Miller K, Hannum WM, Morley T, Proffit WR. Use of recorded interactive seminars in orthodontic distance education. Am J Orthod Dentofacial Orthop 2007; 132:408-414.

${ }^{22}$ Dental Education at the Crossroads:Challenges and Change: The National Academies Press; 1995.

${ }^{23}$ Faraone KL, Garrett PH, Romberg E. A blended learning approach to teaching pre-clinical complete denture prosthodontics. European Journal of Dental Education 2013;17(1):e22-e27.

${ }^{24}$ Trotman C, Bennett E, Scheffler N, Tulloch JC. Faculty recruitment, retention, and success in dental academia. Am J Orthod Dentofacial Orthop 2002; 122:2-8.

${ }^{25}$ Eaton KA, Reynolds PA, Grayden SK, Wilson NHF. A vision of dental education in the third millennium. British Dental Journal 2008; 205:261-271

${ }^{26}$ Zhang D. Interactive multimedia-based E-learning: a study of effectiveness. The American Journal of Distance Education 2005; 19: 149-162.

${ }^{27}$ Wanstreet C. Interaction in online learning environments. The Quarterly Review of Distance Education 2006: 7(4): 399-411

${ }^{28}$ Olapiriyakul K, Scher JM. A guide to establishing hybrid learning courses: employing information technology to create a new learning experience, and a case study. Internet Higher Educ 2006: 9: 287-301. 
${ }^{29}$ Handal B, Groenlund C, Gerzina T. Dentistry students' perceptions of learning management systems. Eur J Dent Educ 2010: 14: 50-54.

${ }^{30}$ Pilcher ES. Students' evaluation of online course materials in fixed prosthodontics: a case study. Eur J Dent Educ 2001: 5: 53-59.

${ }^{31}$ Neuhaus KW, Schegg R, Krastl G, Amato M, Weiger R, Walter C. Integrated learning in dentistry: baseline data and first evaluation at the Dental School of Basel. Eur J Dent Educ 2008: 12: 163-169.

${ }^{32}$ Utts J, Sommer B, Acredolo C, Maher MW, Matthews HR. A study comparing traditional and hybrid internet-based instruction in introductory statistics classes. J Stat Educ 2003: 11. [online] Available at http://www.amstat.org/publications/jse/v11n3/utts.html

${ }^{33}$ Neuhaus KW, Schegg R, Krastl G, Amato M, Weiger R, Walter C. Integrated learning in dentistry: baseline data and first evaluation at the Dental School of Basel. Eur J Dent Educ 2008: 12: $163-169$

${ }^{34}$ Woltering V, Herrler A, Spitzer K, Spreckelsen C. Blended learning positively affects students' satisfaction and the role of the tutor in the problem-based learning process: results of a mixed-method evaluation. Adv Health Sci Educ 2009: 14: 725-738.

35 Bednar ED, Hannum WM, Firestone A, Silveira AM, Cox TD, Proffit WR. Application of distance learning to interactive seminar instruction in orthodontic residency programs. American Journal of Orthodontics and Dentofacial Orthopedics 2007;132(5):586-94.

${ }^{36}$ Chodorow S. Educators must take the electronic revolution seriously. Acad Med.1996;71:22126.

37 Tan PL, Hay DB, Whaites E. Implementing E-learning in a radiological science course in dental education: A Short-Term Longitudinal Study. J Dent Educ 2009: 73: 1202-1212.

${ }^{38}$ Linjawi AL, Hamdan AM, Perryer DG, Walmsley AD, Hill KB.Students' attitudes towards an on-line orthodontic learning resource. Eur J Dent Educ 2009: 13: 87-92.

${ }^{39}$ Gibbard LL, Salajan F. A novel interactive online module in a traditional curriculum through a blended learning approach. Electron J e-earn 2009: 7: 301-308.

${ }^{40}$ Klein K.P., Hannum W.M., Koroluk L.D., Proffit W.R. Interactive distance learning for orthodontic residents: Utilization and acceptability (2012) American Journal of Orthodontics and Dentofacial Orthopedics, 141 (3) , pp. 378-385.

${ }^{41}$ Ginns P, Ellis R. Quality in blended learning: exploring the relationships between on-line and face-to-face teaching and learning. Internet Higher Educ 2007: 10: 53-64. 
${ }^{42}$ Durham JA, Brettell S, Summerside C, McHanwell S. Evaluation of a virtual anatomy course for clinical undergraduates. Eur J Dent Educ 2009: 13: 100-109.

${ }^{43}$ Eckleberry-Hunt J, Tucciarone J.The challenges and opportunities of teaching "generation $\mathbf{y}^{\text {".J }}$ Grad Med Educ. 2011 Dec;3(4):458-61

${ }^{44}$ Bednar ED, Hannum WM, Firestone A, Silveira AM, Cox TD, Proffit WR. Application of distance learning to interactive seminar instruction in orthodontic residency programs. Am J Orthod Dentofacial Orthop. 2007 Nov;132(5):586-94.

${ }^{45}$ Seidl, M. (2005). Blended Learning With Moodle: Didactical and Technical Aspects of Blended Learning Scenario with Moodle. Retrieved from http://streaming.fhstpoelten.ac.at/netties2005/word/Seidl.pdf. On April 28, 2006. 